\title{
Detection of anti-Toxoplasma gondii antibodies in chronic myeloid leukemia and acute myeloid leukemia patients
}

\author{
Mohammad Javad Gharavi ${ }^{1}$, Mona Roozbehani ${ }^{2}$ and Zienat Mandeh ${ }^{1}$ \\ 1. Department of Parasitology, Faculty of Allied Medicine, Iran University of Medical Sciences, Tehran, Iran; \\ 2. Department of Parasitology, School of Medicine, Iran University of Medical Sciences, Tehran, Iran. \\ Corresponding author: Mona Roozbehani, e-mail: mona.roozbehani@yahoo.com \\ Co-authors: MJGH: gharavi_m_j@yahoo.com, ZM: mandehzinat@yahoo.com \\ Received: 21-04-2017, Accepted: 14-08-2017, Published online: 13-09-2017
}

doi: 10.14202/vetworld.2017.1063-1065 How to cite this article: Gharavi MJ, Roozbehani M, Mandeh Z (2017) Detection of anti-Toxoplasma gondii antibodies in chronic myeloid leukemia and acute myeloid leukemia patients, Veterinary World, 10(9): 1063-1065.

\begin{abstract}
Background and Aim: Infection of Toxoplasma gondii is a worldwide distribution. Toxoplasmosis in patients who are immunocompromised by virtue of underlying leukemia disease has received relatively little attention. This study was aimed to evaluate $\operatorname{IgG}$ and $\operatorname{IgM}$ antibodies of $T$. gondii and to minimize the role of $T$. gondii and opportunistic infection complication at the early stage of infection in leukemia patients.
\end{abstract}

Materials and Methods: The purpose of this assay was to measure anti-T. gondii IgG and IgM antibodies by enzymelinked immunosorbent assay (ELISA) technique in leukemia patients.

Results: IgG antibodies against T. gondii were detected by ELISA in 96 (56.4\%) leukemia patients and 72 (42.4\%) control group. IgM antibodies were found in 10 patients $(5.9 \%)$ with leukemia and $3(1.8 \%)$ in the corresponding.

Conclusion: Our finding indicated that leukemia patients under immunosuppressive condition should not be neglected. Toxoplasmosis in leukemia patients as a main risk factor is considered, meanwhile in some patients, due to possibility of the presence of secondary infection that leads to severe toxoplasmosis.

Keywords: acute myeloid leukemia, chronic myeloid leukemia, Toxoplasma gondii.

\section{Introduction}

Toxoplasma gondii is a zoonotic coccidian obligate, intracellular protozoan parasite, which humans and other warm-blooded animals are its hosts [1]. The infection has a worldwide distribution, and the incidence of the disease varies around the world [2]. Humans get $T$. gondii through ingestion of undercooked meat, contact with feline feces, and sometimes through drinking contaminated water, food, and vegetables or through transplantation of infected organ [3]. Human toxoplasmosis is often subclinical or with slight symptom [4]. Moreover, the parasite's bradyzoites can persist inside human cells for long time periods, but recent infection can be reactivated, such as in the case of AIDS which T. gondii reactivation causes severe encephalitis [5]. In this regard, the prevalence of $T$. gondii can induced encephalitis to reach up to $40 \%$ in patients with AIDS in which $10-30 \%$ die from this parasitic disease [6].

This protozoan has occasionally observed in patients with neoplasias or transplantation recipients

Copyright: Gharavi, et al. Open Access. This article is distributed under the terms of the Creative Commons Attribution 4.0 International License (http://creativecommons.org/licenses/ by/4.0/), which permits unrestricted use, distribution, and reproduction in any medium, provided you give appropriate credit to the original author(s) and the source, provide a link to the Creative Commons license, and indicate if changes were made. The Creative Commons Public Domain Dedication waiver (http:// creativecommons.org/publicdomain/zero/1.0/) applies to the data made available in this article, unless otherwise stated. who are under immunosuppressive therapy. In these patients, the disease resulted in the reactivation of chronic infection. The acute infection, in patients with disseminated disease, often involves the central nervous system, with diffuse encephalopathy and meningoencephalitis including cerebral mass lesions $[7,8]$. Toxoplasmosis in patients who are immunocompromised by virtue of underlying leukemia disease has received relatively little attention. Leukemia is a disease resulting from the neoplastic proliferation of hemopoietic including lymphoid cells. It results from mutation, or epigenetic factors lead into clonal expansion. The clinical advent is flaw cells that are usually, directly, or indirectly, to the proliferation [9].

Drug induces immunosuppressive leukemia patients, to assess the risk of secondary severe toxoplasmosis. Therefore, This study was aimed to evaluate $\operatorname{IgG}$ and $\operatorname{IgM}$ antibodies of T. gondii and to minimize the role of $T$. gondii and opportunistic infection complication at the early stage of infection in leukemia patients.

\section{Materials and Methods \\ Ethical approval}

This project underwent ethical review and was approved by the Ethics Committee of Iran University of Medical Sciences.

\section{Subjects}

A cross-sectional serosurvey of $T$. gondii antibodies in 170 (65 men and 105 women) patients 
with leukemia disorders from the Oncology and Haematology Department, Shariati Hospital, Tehran, Iran, and Fardis Central Laboratory, in Alborz Province of Iran, between October 2014 and March 2015, in parallel 170 healthy volunteers with identical age and sex match individual, were selected as corresponding control. Our samples consisted of both chronic myeloid leukemia (CML) and acute myeloid leukemia (AML). Peripheral blood was taken from all leukemia patients and control group under aseptic conditions, and the sera were separated and stored at $-20^{\circ} \mathrm{C}$ without any discrepancy.

\section{Serological technique}

Enzyme-linked immunosorbent assay (ELISA) was used for the assessment of anti-T. gondii IgG and IgM antibodies. The ELISA kit was provided by Euroimmun, a commercial manufacturer in Germany. The test performed base on the manufacturer's guideline. The absorbance of serum samples was divided into the absorbance of the low calibrator. The ratio above $1 / 1$ was considered as positive for both $\operatorname{IgM}$ and IgG antibodies, respectively.

\section{Statistical analysis}

The statistical evaluation was based on Chisquared test by SPSS version 16 for Windows pocket program. A $\mathrm{p}<0.05$ was considered as statistically significant.

\section{Results}

In this study, the age of leukemia patients was 10-60 years old. Table-1 summarized the distribution of CML and AML myelogenous leukemia patients. $38 \%$ of patients were male and $62 \%$ of patients were female. $T$. gondii $\mathrm{IgG}$ antibodies were assessed by ELISA in 96 (56.4\%) leukemia patients and $72(42.4 \%)$ control group. IgM antibodies were detected in 10 leukemia patients $(5.9 \%)$ and $3(1.8 \%)$ in control group. The seroprevalence distributions of the two groups were shown in Table-2. IgG antibodies of T. gondii were found in $40(41.6 \%)$ male and $56(58.4 \%)$ female leukemia patients. IgM antibodies of $T$. gondii were found in $3(30 \%)$ male and $7(70 \%)$ female leukemia patients. The difference in the IgG seropositivity rate between the patient and the control group is statistically significant $(\mathrm{p}<0.05)$. The seropositivity rate of anti- $T$. gondii IgM was higher in the patients group and statistically significant $(\mathrm{p}<0.05)$ (Table-2).

\section{Discussion}

One of the most critical problems in leukemia is infectious diseases which may lead the patient succumbs to sudden death. The active infection may alter the normal immune response of the host. Granulocytes and macrophages play a main role immune surveillance in innate immune system [10]. In this study, immunocompromised patients were found more frequently infected with $T$. gondii revealed by seropositivity both $\operatorname{IgG}$ and IgM anti-T. gondii in compare to corresponding control $(\mathrm{p}<0.05)$.

In fact, leukemia patients demonstrated that $\operatorname{IgM}$ and $\operatorname{IgG}$ anti-T. gondii antibodies were $10(5.9 \%)$ and 96 (56.4\%), respectively. In line with, control group, result showed IgM and $\operatorname{IgG}$ anti-T.gondii antibodies were $3(1.8 \%)$ and $72(42.4 \%)$. It is in trigging to note the level of IgG and IgM antibodies were consistently moderate higher in leukemia patients than control groups $(\mathrm{p}<0.05)$. This is indicative of possible reactivation of $T$. gondii infection in leukemia patients.

This is in compromise with the studies reported by Yazar et al. [11] in which patients neoplasia demonstrate superior value of $T$. gondii $\operatorname{IgG}$ and $\operatorname{IgM}$ antibodies seropositive $(52.9 \%)$ considered the control group (20\%) [11].

Furthermore, other research showed $T$. gondii IgG antibodies in $114(45.2 \%)$ cancer patients

Table-1: Patients age distribution.

\begin{tabular}{lccccc}
\hline Age groups (years) & \multicolumn{2}{c}{$\mathbf{n}$} & & \multicolumn{2}{c}{$\mathbf{n}(\%)$} \\
\cline { 2 - 3 } & CML & AML & & Frequency patients & Frequency healthy volunteers \\
\hline $11-20$ & 4 & 21 & & $25(14.7)$ & $22(12.9)$ \\
$21-30$ & 7 & 32 & & $39(22.9)$ & $35(20.6)$ \\
$31-40$ & 8 & 23 & & $31(18.2)$ & $30(17.6)$ \\
$41-50$ & 16 & 12 & & $28(16.4)$ & $32(18.8)$ \\
$51-60$ & 20 & 11 & & $31(18.2)$ & $33(19.4)$ \\
$>60$ & 12 & 4 & & $16(9.4)$ & $18(10.6)$ \\
Total & 67 & 103 & & $170(100)$ & $170(100)$ \\
\hline
\end{tabular}

$\mathrm{CML}=$ Chronic myeloid leukemia, $\mathrm{AML}=$ Acute myeloid leukemia

Table-2: The result of serosurvey for T. gondii antibodies of leukemic patients and the control group.

\begin{tabular}{|c|c|c|c|c|c|c|}
\hline \multirow[t]{2}{*}{ Antibody } & \multicolumn{3}{|c|}{ Leukemic patients n (\%) } & \multicolumn{3}{|c|}{ Control group n (\%) } \\
\hline & $n=170$ & Male & Female & $n=170$ & Male & Female \\
\hline Anti-T. gondii IgG & $96(56.4)$ & $40(41.6)$ & $56(58.4)$ & $72(42.4)$ & $30(41.6)$ & $42(58.3)$ \\
\hline Anti-T. gondii IgM & $10(5.9)$ & $3(30)$ & $7(70)$ & $3(1.8)$ & $1(33.3)$ & $2(66.6)$ \\
\hline
\end{tabular}

T. gondii=Toxoplasma gondii, IgG=Immunoglobulin G , IgM=Immunoglobulin M 
were positive, and $T$. gondii $\operatorname{IgM}+$ antibodies were $26(10.3 \%)$ as well as $17(6.7 \%)$ of specimens had both IgG and IgM antibodies. In control group, 92 (36.5\%) cases and $15(6 \%)$ cases revealed seropositive for $\operatorname{IgG}$ and IgM antibodies, respectively [12].

Furthermore, Gharavi et al. [13] assessed IgM and $\mathrm{IgG}$ anti-T. gondii in renal transplant recipients, before and after transplantation. ELFA method detected $65(63.7 \%)$ pre-transplantation specimens as IgG + and did not detect any IgM + . Nevertheless, IgM was detected in $3(2.9 \%)$ post-transplantation samples.

Moreover, additional studies indicated that the difference frequency of positive IgG antibodies between the patients with cancer and the control group was significant, whereas the positivity rates of $\operatorname{IgM}$ did not show any significant difference [6].

These findings may suggest that leukemic patients under immunosuppressive condition had been infected with $T$. gondii before initiation of leukemia development.Therefore, the immunosuppressive therapy may provide an opportunity for the inactive infection to undergo to full-blown toxoplasma disease. According to our finding, leukemic patients as a group of patients being treated with immunosuppressed drugs should not be neglected. However, further studies such as antigen detection and gene amplification (polymerase chain reaction) may facilitate to elucidate the activity of $T$. gondii in immunocompromised patients.

\section{Authors' Contributions}

MR and MJGH have designed the concept and supervised the plan of work and also have prepared the manuscript. ZM has contributed in sample collection, and technical methods. MR and MJGH have analyzed and interpreted the data. All authors read and approved the final manuscript.

\section{Acknowledgments}

This project was granted by the Research Assistance of Iran University of Medical Sciences (Grant Project No. 18638). The authors are grateful to the individuals, directors, and staff of the Fardis Central Laboratory and Shariati hospitals who provided us with some sera.

\section{Competing Interests} interests.

The authors declare that they have no competing

\section{References}

1. Liu, Q., Singla, LD. and Zhou, H. (2012) Vaccines against Toxoplasma gondii: Status, challenges and future directions. Hum. Vaccin. Immunother., 8(9): 1305-1308.

2. Moncada, PA. and Montoya, JG. (2012) Toxoplasmosis in the fetus and newborn: An update on prevalence, diagnosis and treatment. Expert Rev. Anti. Infect. Ther, 10(7): 815-828.

3. Liu, Q., Wang, Z., Huang, S. and Zhu, XQ. (2015) Diagnosis of toxoplasmosis and typing of Toxoplasma gondii. Parasit. Vectors., 28(8): 292.

4. Blader, I.J., Coleman, B.I., Chen, C.T. and Gubbels, M.J. (2015) Lytic cycle of Toxoplasma gondii: 15 years later. Annu. Rev. Microbiol., 69: 463-485.

5. Gangneux, F., Sterkers, Y., Year, H., Accoceberry, I., Menotti, J. and Cassaing, S. (2015) Molecular diagnosis of toxoplasmosis in immunocompromised patients: A 3-year multicenter retrospective study. J. Clin. Microbiol., 53(5): 1677-1684.

6. Yuan, Z., Gao, S., Liu, Q., Xia, X., Liu, X., Liu, B. and Hu, R. (2007) Toxoplasma gondii antibodies in cancer patients. Cancer Lett., 254(1): 71-74.

7. Evering, T. and Weiss, L.M. (2006) The immunology of parasite infections in immunocompromised hosts. Parasite Immunol., 28(11): 549-565.

8. Ferreira, M.S. and Borges, A.S. (2002) Some aspects of protozoan infections in immunocompromised patients. Mem. Inst. Oswaldo Cruz, 97(4): 443-457.

9. McPherson, R.A. and Pincus, M.R. (2011) Henry's Clinical Diagnosis and Management by Laboratory Methods. $22^{\text {nd }}$ ed. Saunders, W.B, America. p656-660.

10. Gharavi, M.J., Shraf, F., Vosough, P. and Rokni, M.B. (2003) Survey of intestinal parasitic infection in leukemic children and evaluation of their serum immunoglobulins. Iran. J. Public Health, 32(1): 19-21.

11. Yazar, S., Yaman, O., Eser, B., Altuntas, F., Kurnaz, F. and Sahin, I. (2004) Investigation of anti-Toxoplasma gondii antibodies in patients with neoplasia. J. Med. Microbiol., 53: 1183-1186.

12. Ghasemian, M., Maraghi, S.H., Saki, J. and Pedram, M. (2007) Determination of antibodies (IgG, IgM) against Toxoplasma gondii in patients with cancer. Iran. $J$. Parasitol., 2(4):1-6.

13. Gharavi, M.J., Jalali, S., Khademvatan, S.H. and Heydari, S. (2011) Detection of $\operatorname{IgM}$ and $\operatorname{IgG}$ anti Toxoplasma antibodies in renal transplant recipient using ELFA, ELISA and ISAGA methods: Comparison of preand post-transplantation status. Ann. Trop. Med. Parasitol., 105(5): 367-371. 